\title{
Role of Platelet count as important prognostic marker in Pregnancy Induced Hypertension
}

\author{
Dr.M.A.Sameer ${ }^{1}$, Dr.D.P.Meshram ${ }^{2}$, Dr.S.A.Deshpande ${ }^{3}$, Dr.D.Sadhu ${ }^{4}$, \\ Dr.Pandit $S^{4}$ \\ ${ }^{I}$ (Associate Professor,Department of Pathology, Dr.S.C.G.M.C,Nanded, India) \\ ${ }^{2}$ (Assistant Professor,Department of Pathology, Dr.S.C.G.M.C,Nanded, India) \\ ${ }^{3}$ (Professor and head, Department of Pathology, Dr.S.C.G.M.C,Nanded, India) \\ ${ }^{4}$ (Post Graduate resident, Department of Pathology, Dr.S.C.G.M.C,Nanded, India)
}

\begin{abstract}
Introduction: Pregnancy induced hypertension (PIH) includes gestational hypertension, pre eclampsia and eclampsia. It occurs in approximately 11-29\% pregnancies in indian population. Amongst all the parameters platelet count is the most simple and cost effective method for prediction of PIH, way before the appearance of derangements in PT, APTT and TT values. The study soughts the importance of platelet count as the most consistent and reliable method in early detection of PIH cases.

Materials and methods:

A prospective study was conducted in 200 cases and 80 controls over a period of 2 years. The bleeding time, clotting time, hemoglobin estimation and paltelet count were performed.

Observations:

The platelet count in severe preeclampsia and eclampsia was significantly lower than in mild pre eclampsia and controls. Thrombocytopenia was seen in total of 33 cases of severe pre-eclampsia and eclampsia combined out of which 30 (90.90\%) had unfavourable fetal outcome and 27 (81.81\%) had poor maternal outcome.

Conclusion:

Simple and routine tests like $C B C$ and platelet count are highly helpful in suspecting a deranged coagulation status early in the course of the disease and plan preemptive management strategies that has been proven to have a crucial role in reducing the morbidity and mortality of both mother and fetus.
\end{abstract}

Key words: maternal,morbidity,mortality, platelet,PIH.

\section{Introduction}

1.1 Preeclampsia is defined as a multisystem disorder occuring in pregnancy and the puerperium which is characterized by development of hypertension of $140 / 90 \mathrm{mmHg}$ and above after the $20^{\text {th }}$ week in a previously normotensive patient. Approximately $70 \%$ of hypertensive disorders are due to gestational hypertension, preeclampsia and eclampsia whereas other $30 \%$ are due to preexisting or undiagnosed hypertension. ${ }^{[1]}$ Majority of these conditions are preventable with good antenatal care, but looking at rural areas in country like India or many other Asian and sub-Saharan continents, the scene is still gloomy.

1.2 Profound changes in the coagulation and fibrinolytic system occur during normal pregnancy causing a hypercoagulable state. There is a definite exaggeration of the hypercoagulable state of pregnancy during Pregnancy Induced Hypertension (PIH). Out of all the haematological abnormalities that occur in PIH, thrombocytopenia is the most common seen to occur in $11 \%$ to $29 \%$ of patients ${ }^{[2,3]}$. These pregnancies also are associated with qualitative changes suggesting increased platelet production and destruction. There is a shortened platelet life span, increased numbers of megakaryocytes in the bone marrow, and an increased number of immature platelets seen in the peripheral blood smear ${ }^{[4,5]}$. The frequency and intensity of maternal thrombocytopenia varies and is dependent on the intensity of the disease process and duration of PIH syndrome ${ }^{[6,7]}$. Overt thrombocytopenia, defined by a platelet count less than $100,000 / \mathrm{L}$, indicates severe disease. ${ }^{[8]}$ In general, the lower the platelet counts, the higher the maternal and fetal morbidity and mortality. In most cases, delivery is indicated because the platelet count continues to decrease.

1.3 It is observed that preeclamptic mother having coagulation indices in severely abnormal ranges were associated with substantial maternal and fetal jeopardy. ${ }^{[9,10]}$ Early assessment of severity of pre-eclampsia and eclampsia is necessary to prevent complications like HELLP syndrome and increased maternal and fetal morbidity and mortality. Hence, this study is undertaken to assess the severity of pre-eclampsia, eclampsia and coagulopathy by estimation of platelet count, that is a simple, rapid, cheaper and easily available prognostic lab method, so as to prevent further complications and help in better outcomes of motherhood. 


\section{Methods And Materials}

2.1 Total 280 cases were included in the study for a period of 2 years during jan-2011 to dec-2012 at Shankarrao Chavan Govt Medical College, Nanded.

2.2 Healthy normotensive pregnant females in the third trimester of pregnancy, without any signs and symptoms of pregnancy induced hypertension were considered as controls. Pregnant females in the third trimester with symptoms and signs of pregnancy induced hypertension, admitted in Antenatal care ward were selected and grouped as per the criteria described in classification of hypertensive disorders of pregnancy according to the American College of Obstreticians and Gynaecologists. ${ }^{[11]}$

2.3 The study groups were divided as follows

1. Healthy normotensive pregnant controls-80

2. Patients with mild preeclampsia-106

3. Patients with severe preeclampsia-58

4. Patients with eclampsia-36 proforma.

Detail history, important clinical findings and relevant investigations were noted as per the case

2.4 Whole blood sample was obtained by venepuncture of the Anterior cubital vein. The blood sample was obtained without a pressure cuff, allowing blood to enter the syringe by continuous free flow by the negative pressure from an evacuated tube. The 22 Gauge size needle and good quality $10 \mathrm{ml}$ disposable plastic syringe was used for the collection of blood.

2.5 The hematological investigations were performed on a fully automated Orphee Mythic- 18 three part differential cell counter. All the details were recorded in the case proforma.

\section{Observation}

3.1. In controls, the maximum number were seen in the age group of 21-25 yrs i.e. 46 (57.5\%) Mean age was found to be 24.41 yrs. Similarly maximum number of patients with mild preeclampsia, severe pre eclampsia and eclampsia were in the age group of 21-25 years Mean age of patients with mild pre eclampsia was 24.43 yrs, severe pre-eclampsia was 24.55 and that with eclapmsia was $24.30 \mathrm{yrs}$.

3.2 Out of 80 controls, maximum i.e. $51(63.75 \%)$ were primigravida. Out of total 200 cases, most of the cases i.e. 133 cases $(66.50 \%)$ were primigravidae and 67 cases $(33.50 \%)$ were multigravidae. In mild preeclampsia, most of the patients i.e. 70 cases $(66.03 \%)$ were primigravidae while 36 cases $(33.97 \%)$ were multigravidae. In severe preeclampsia, maximum cases i.e. 38 women $(65.51 \%)$ were primigravidae while 20 cases $(34.49 \%)$ were multigravidae. Similarly in eclampsia, 25 women $(69.44 \%)$ were primigravidae, 11 women $(30.56 \%)$ were multigravidae.

3.3. The mean gestational age in control was $37.30 \mathrm{wk}$ with the range of $34-39$ wks. While the mean gestational age in mild preeclampsia, severe preeclampsia, and eclampsia was 35.26 wks, 34.03 wks, 32.38 wks respectively.

3.4. The mean blood pressure in controls was $127.05 / 82.35$. In mild pre eclampsia it was found to be $149.43 / 96.37 \mathrm{~mm} \mathrm{Hg}$, in severe pre eclampsia it was $167.55 / 115.72$ and that of eclampsia was $171.33 / 119.5 \mathrm{~mm}$ Hg.

3.5. The mean hemoglobin of controls was $10.03 \mathrm{gm} \%$. Platelet count was $2.42 \pm 0.62 \mathrm{lakh} / \mathrm{cumm}$ (Range-1.54-3.85). Bleeding time was $2.43 \pm 0.21 \mathrm{~min}$ (Range2.00-3.16) and clotting time was $5.28 \pm 0.91 \mathrm{~min}$ (Range 3.75-7.5).

3.6. Mean Hemoglobin in mild pre eclampsia, severe pre eclampsia and eclampsia was found to be $10.01 \mathrm{gm} \%, 9.08 \mathrm{gm} \%, 9.85 \mathrm{gm} \%$ respectively. The difference in mean $\mathrm{Hb}$ was not statistically significant with severity of pregnancy induced hypertension.

3.7. The bleeding time in mild preeclampsia was $2.45 \pm 0.29$ min (Range-2.08-3.16; $\mathrm{P}$ value $=0.756$ ), in severe preeclampsia it was $2.66 \pm 1.35$ min (Range-2.08-7.91; $\mathrm{P}$ value $=0.154)$ and in eclampsia it was $2.70 \pm 1.44$ min (Range-2.08-7.58, $\mathrm{P}$ value $=0.109)$. Bleeding time was not prolonged significantly $(\mathrm{P}>0.05)$ except in 4 cases of severe preeclampsia (6.89\%) and 3 cases of eclampsia (8.33\%).

3.8. The clotting time in mild preeclampsia was $5.49 \pm 1.06$ min $(\mathrm{R}-4.08-7.5 ; \mathrm{P}$ value $=0.169)$ and in severe preeclampsia was $5.60 \pm 1.06 \mathrm{~min}(\mathrm{R}-4.08-8.5 ; \mathrm{P}$ value $=0.0603)$ and in eclampsia, it was $5.65 \pm 1.18 \mathrm{~min}$ (R-4.08-9; $\mathrm{P}$ value $=0.0683)$. Clotting time was not prolonged significantly $(\mathrm{P}>0.05)$ except in 4 cases of severe preeclampsia $(6.89 \%)$ and 3 of eclampsia $(8.33 \%)$.

3.9. The platelet count in mild preeclampsia was not significantly lower than that in controls. It was $2.39 \pm 0.61 \mathrm{lakh} /$ cumm (Range-1.38-3.85) with $\mathrm{P}$ value $=0.7252$. It has been seen that the platelet count in severe preeclampsia and eclampsia was very significantly lower than that in normal healthy pregnant controls. The mean platelet count in severe preeclampsia and eclampsia was $1.60 \pm 0.51$ lakh/cumm (Range-0.38-2.21) 
with $\mathrm{P}<0.001$ and $1.51 \pm 0.68$ lakh/cumm (Range-0.41-2.54) with $\mathrm{P}<0.001$. Reduced platelet count was seen in 2 cases $(1.89 \%)$ of mild pre-eclampsia, 17 cases $(29.31 \%)$ of severe preeclampsia and 16 cases $(44.44 \%)$ of eclampsia.

3.10. Out of 33 cases with thrombocytopenia, 30 women $(90.90 \%)$ had unfavourable fetal outcome while out of 61 women with normal coagulation profile, $15(24.59 \%)$ had unfavourable fetal outcome. Chi square value is 40.92 i.e $\mathrm{P}<0.0001$, with $\mathrm{df}=1$, which suggests that derangement in coagulation profile is very significantly associated with fetal morbidity and mortality

\section{Figures And Tables}

Table 1. Parity wise distribution of controls and cases.

\begin{tabular}{|l|l|l|l|}
\hline Status & Primigravida(\%) & Multigravida(\%) & Total(\%) \\
\hline Controls & $51(63.75)$ & $29(36.25)$ & $80(100)$ \\
\hline Mild pre-eclampsia & $70(66.03)$ & $36(33.97)$ & $106(100)$ \\
\hline Severe pre-eclampsia & $38(65.51)$ & $20(34.49)$ & $58(100)$ \\
\hline eclampsia & $25(69.44)$ & $11(30.56)$ & $36(100)$ \\
\hline Total & $184(64.71)$ & $96(34.29)$ & $280(100)$ \\
\hline
\end{tabular}

Table 2. Mean Hb, platelet count, Bleeding time (BT), and clotting time (CT) of controls and cases.

\begin{tabular}{|c|c|c|c|c|}
\hline Tests & $\begin{array}{l}\text { Control } \\
(\mathrm{n}=80)\end{array}$ & $\begin{array}{ll}\begin{array}{l}\text { Mild } \\
(\mathrm{n}=106)\end{array} & \text { PE }\end{array}$ & $\begin{array}{l}\text { Severe PE } \\
(\mathrm{n}=58)\end{array}$ & $\begin{array}{l}\text { Eclampsia } \\
(\mathrm{n}=36)\end{array}$ \\
\hline Mean $\mathrm{Hb}(\mathrm{gm} \%)$ & 10.03 & 10.01 & 9.08 & 9.85 \\
\hline $\begin{array}{l}\text { Platelet count } \\
\text { (lac/cmm) }\end{array}$ & $2.42 \pm 0.62$ & $2.39 \pm 0.61$ & $1.60 \pm 0.51 \downarrow$ ** & $1.51 \pm 0.68 \downarrow * *$ \\
\hline $\begin{array}{l}\text { Thrombocytopenia } \\
\text { cases }\end{array}$ & -- & $2(1.89 \%)$ & $17(29.31 \%)$ & $16(44.44 \%)$ \\
\hline $\begin{array}{l}\text { BT }(\min ) \\
\text { Prolonged BT cases }\end{array}$ & $\begin{array}{l}2.43 \pm 0.21 \\
--\end{array}$ & $\begin{array}{l}2.45 \pm 0.29 \\
--\end{array}$ & $\begin{array}{l}2.66 \pm 1.35 \\
4(6.89 \%) \\
\end{array}$ & $\begin{array}{l}2.70 \pm 1.44 \\
3(8.33 \%) \\
\end{array}$ \\
\hline $\begin{array}{l}\text { CT (min) } \\
\text { Prolonged } \quad \text { CT cases }\end{array}$ & $\begin{array}{l}5.28 \pm 0.91 \\
--\end{array}$ & $\begin{array}{l}5.49 \pm 1.06 \\
--\end{array}$ & $\begin{array}{l}5.60 \pm 1.06 \\
4(6.89 \%) \\
\end{array}$ & $\begin{array}{l}5.65 \pm 1.18 \\
3(8.33 \%)\end{array}$ \\
\hline
\end{tabular}

Table.3. Correlation of platelet count with maternal outcome in cases of severe preeclampsia and eclampsia combined.

\begin{tabular}{|l|l|l|l|}
\hline Platelet count & No of cases & Unfavorable Maternal Outcome & Favorable maternal Outcome \\
\hline Normal & 61 & $7(11.47 \%)$ & $54(88.52 \%)$ \\
\hline Thrombocytopenic & 33 & $27(81.81 \%)$ & $6(18.18 \%)$ \\
\hline
\end{tabular}

Table 4. Correlation of platelet count with fetal outcome in cases of severe preeclampsia and eclampsia combined.

\begin{tabular}{|l|l|l|l|}
\hline Platelet count & No. of cases & $\begin{array}{l}\text { Unfavourable Fetal out } \\
\text { come }\end{array}$ & $\begin{array}{l}\text { Favourable fetal } \\
\text { Outcome }\end{array}$ \\
\hline Normal & 61 & $15(24.59 \%)$ & $46(75.41 \%)$ \\
\hline Thrombocytopenic & 33 & $30(90.90 \%)$ & $3(9.09 \%)$ \\
\hline
\end{tabular}

Table.5 comparison of platelet count in present study with other studies in controls and cases.

\begin{tabular}{|c|c|c|c|c|}
\hline Authors & Control (lac/cmm) & $\begin{array}{l}\text { Mild PE } \\
(\text { lac/cmm) }\end{array}$ & $\begin{array}{ll}\begin{array}{l}\text { Severe } \\
(\mathrm{lac} / \mathrm{cmm})\end{array} & \text { PE } \\
\end{array}$ & $\begin{array}{l}\text { Eclampsia } \\
(\mathrm{lac} / \mathrm{cmm})\end{array}$ \\
\hline Srivastava $(1995)^{[12]}$ & 1.94 & 1.79 & $1.64 \downarrow^{*}$ & $1.52 \downarrow *$ \\
\hline Jambhulkar et al (2001) ${ }^{[13]}$ & 2.38 & 2.30 & $1.70 \downarrow *$ & $1.51 \downarrow * *$ \\
\hline Joshi et al $(2004)^{[14]}$ & 2.2 & 2.0 & $1.40 \downarrow^{*}$ & $1.30 \downarrow^{* *}$ \\
\hline J. Davies et al (2007) ${ }^{[15]}$ & 2.57 & 2.30 & $1.77 \downarrow *$ & -- \\
\hline Ellora Devi et at (2012) ${ }^{[16]}$ & 2.44 & 1.82 & $1.42 \downarrow * *$ & - \\
\hline $\begin{array}{l}\text { Present study } \\
\text { (2012) }\end{array}$ & 2.42 & 2.39 & $1.60 \downarrow^{* *}$ & $1.51 \downarrow * *$ \\
\hline
\end{tabular}

$\downarrow^{*}$ - $\mathrm{P}<0.05$-significantly low, $\uparrow * *$-P $<0.01$-very significantly low 


\section{Discussion}

5.1 Srivastava (1995) ${ }^{[12]}$ reported mean platelet count of 1.94 lakh/cumm in normal pregnant control, $1.79 \mathrm{lakh} / \mathrm{cumm}$ in mild preeclampsia, \& significantly low platelet count in severe preeclampsia i.e. 1.64 lakh/cumm and in eclampsia i.e. 1.52 lakh/cumm. Jambhulkar et al ${ }^{[13]}$ (2001) reported significantly lower platelet count in severe preeclampsia $(1.70 \mathrm{lakh} / \mathrm{cumm}, \mathrm{P}<0.05)$ and in eclampsia $(1.5133 \mathrm{lakh} / \mathrm{cumm}, \mathrm{P}<0.05)$. S. Joshi et al (2004) ${ }^{[14]}$ reported platelet count 2.2 lakh/cumm in control group, 2.0 lakh/cumm in mild preeclampsia, $1.40 \mathrm{lakh} / \mathrm{cumm}$ in severe preeclampsia and $1.30 \mathrm{lakh} / \mathrm{cumm}$ in eclampsia. The severe preeclampsia showed a significant low count with $\mathrm{P}<0.05$ \& eclampsia was found to be very significantly lowered with a $\mathrm{P}<0.01$. J.Davies ${ }^{[15]}$ reported a mean of $2.57 \mathrm{lakh} / \mathrm{cmm}$ for controls, $2.30 \mathrm{lakh} / \mathrm{cmm}$ for mild pre eclampsia and significant low count of $1.77 \mathrm{lakh} / \mathrm{cmm}$ for severe pre eclampsia. Similarly Ellora Devi et al $(2012)^{[16]}$ mentioned the mean platelet count of $2.44 \mathrm{lakh} / \mathrm{cmm}, 1.82 \mathrm{lakh} / \mathrm{cmm}$ for controls \& mild pre eclampsia respectively and significantly lower for severe pre eclampsia with a count of $1.42 \mathrm{lakh} / \mathrm{cmm}$.

5.2 In present study, the platelet count was very significantly lower in severe preeclampsia $(\mathrm{P}<0.01)$ and eclampsia $(\mathrm{P}<0.01)$ than that in normal healthy pregnant controls. Whereas the platelet count in mild preeclampsia was not significantly lower than the healthy pregnant control.

5.3 Our finding of a trend of lowering of platelet count with increasing severity of pregnancy induced hypertension is consistent with Srivastava $(1995)^{[12]}$, Jambhulkar $(2001)^{[13]}$, Joshi et al $(2004)^{[14]}$, J.Davies et al $(2007)^{[15]}$ and Ellora Devi et al $(2012)^{[16]}$.

5.4 L. A. Norris (1993) ${ }^{[17]}$ found association between platelet activation and intrauterine growth retardation. Leduc et al (1992) ${ }^{[18]}$ reported significant association between thrombocytopenia and maternal complications and reported that platelet nadir is the best predictor of maternal outcome. Savita et al $(2009)^{[19]}$ reported higher incidence of neonatal complications in patients with preeclampsia and thrombocytopenia. Our findings regarding the relation of the deranged coagulation profile and maternal and fetal outcome are consistent with all the studies mentioned above.

\section{Conclusion}

6.1 The hypertensive diseases complicating pregnancy still remains the major problem in developing countries. The fact that pregnancy induced hypertension is largely a preventable condition is established by observing the negligible incidence of pre-eclampsia and eclampsia with the institution of early management.

6.2 In present study we observed a specific pattern of disease and its related variation in coagulation status. Simple and routine tests like CBC and platelet count are highly helpful in suspecting a derangement in the coagulation status early in the course of the disease and plan preemptive management strategies.

6.3 The early detection of compromised status combined with the institution of prompt treatment has been proven to have a crucial and definite role in reducing the morbidity and mortality of both mother and fetus..

\section{References}

[1]. Sibai. B.M. Hypertension in pregnancy. Clinical Obstet Gynecol, 1999:421-436

[2]. Gibson G, Hunter D, Neame PB, Kelton JG. Thrombocytopenia in pre-eclampsia and eclampsia. Semin Thromb Hemost. 1982;8:234-247.

[3]. Pritchard JA, Cunningham FG, Mason RA. Coagulation changes in eclampsia: their frequency and pathogenesis. Am J Obstet Gynecol. 1976;8:855-864.

[4]. Burrows RF, Hunter DJS, Andrew M, Kelton JG. A prospective study investigating the mechanism of thrombocytopenia in preeclampsia. Obstet Gynecol. 1987;70:334-338.

[5]. Saleh AA, Bottoms SF, Welch RA, Ali AM, Mariona FG, Mammen EF Preeclampsia, delivery and the hemostatic system. Am J Obstet Gynecol. 1987;1 57:331-336.

[6]. Heilmann L, Rath W, Pollow K:H hemostatic abnormalities in patients with severe preeclampsia. Clin appl thromb hemost 13:285, 2007

[7]. Hupuczi P, Nagy B, Sziller i et al.: Characteristic laboratory changes in pregnancies complicated by hellp syndrome. Hypertens pregnancy 26: 389, 2007

[8]. Leduc L, Wheeler JM, Kirshon B, et al: Coagulation profile in sever preeclampsia. Obstet gynecol 79:14, 1992

[9]. James M. Roberts, Christopher W, G. Redman pre-eclampsia: More than pregnancy induced hypertension. Lancet, 1993; 341:144750.

[10]. Howie PW, Purdie DW, Begg CB, Prentice CRM. Use of coagulation tests to predict the clinical progrss of pre-eclampsia. The Lancet, 1976 2:323-325.

[11]. Practice Guidelines ACOG Practice Bulletin on Diagnosing and Managing Preeclampsia and Eclampsia http://www.aafp.org/afp/2002/0715/p330.html

[12]. Srivastava M; Bali S; Pandey J; Nayar V; Talib VH; Pregnancy induced hypertension and antithrombin III. Indian J Pathol Microbiol $1995 \mathrm{Jul} ; 38(3): 257-60$.

[13]. Jambhulkar S, Shrikhande A, Shrivastava R, Deshmukh K. Coagulation profile in pregnancy induced hypertension. Indian Journal of Hematology \& blood transfusion, 2001Mar; 19(1):3-5.

[14]. Joshi et al Platelet estimation: its prognostic value in pregnancy induced hypertension. Indian J Physiol Pharmacol 2004; 51 (2): $160-164$ 
[15]. J.Davies, Fernando, Hallworth; Hemostatic Function in Healthy Pregnant and pre- eclamptic women: An assessment using the platelet function analyser (PFA-100) and thromboelastograph; International Anesthesia Research Society; vol.104, no.2, February 2007.

[16]. Dr Ellora Devi; Combination Of Platelet \& Uric Acid Estimation Can Predict Severity Of Pih Better; Int J Pharm Bio Sci 2012 July; 3(3): (B) $1039-1045$

[17]. L.A.Norris, B.L. Sheppard, G. Burke, J. Bonnar. Platelet activation in normotensive and hypertensive pregnancies complicated by intrauterine growth retardation, International journal of obstetrics and gynaecology, 1993; vol 101(3); 209-214.

[18]. Leduc L, Wheeler JM, Krishan B, Mitchell P, Cotton DB. Coagulation Profile In Sever preeclampsia. Obs Gyn . 79 (1) : $14-$ 18,1992 .

[19]. Savita Rani Singhal,Deepika,Anshu,Smiti Nanda; Maternal and Perinatal Outcome in Severe Pre-eclampsia and Eclampsia JSAFOG; september-december 2009;1(3):25-28. 